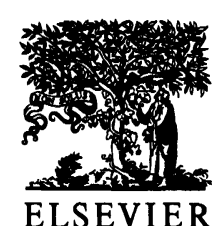

ELSEVIER
Journal of Back and Musculoskeletal Rehabilitation

\title{
Editorial
}

\section{Narcotics for Benign Pain? Never!}

A bill recently passed with a close vote by the Ohio Legislature and is now on the Governor's desk. It purports to provide protection to the physicians who prescribe narcotics to their patients for 'intractable' pain. Examples in the discussion of the bill were largely limited to terminal cancer patients, but the application implied was to any 'chronic pain' person who is 'disabled' by pain.

This is, of course, outrageous.

A 'chronic pain' patient is disabled by the reaction to the circumstances surrounding the pain, i.e. job implications, prognosis, family concerns, etc. Trying to ameliorate the pain with narcotics (or spinal cord stimulator, morphine pump) is not only inappropriate but it's also downright 'stupid'. It's only symptomatic treatment for a complex disabling condition which needs a comprehensive interdisciplinary management approach.

Unfortunately, this bill can (or will) be used by physicians to commit many chronic pain patients to a life of nausea, confusion, and dim consciousness.

A classic example was presented by the television news show ' 60 Minutes' recently. The patient was complaining of low back pain extending to 'total body pain' and Ed Bradley was overly solici- tous as he lambasted the State Medical Board for their decision to suspend the physician's license to practice. He went on to criticize the Pharmacy Board for doing the same thing to the pharmacist who was dispensing hundreds of thousands of oral narcotics to this physician's chronic pain patients - usually secondary to industrial accidents (or, in some cases, victims of the medical/surgical system).

Not incidentally, an interdisciplinary team is NOT the same as a multidisciplinary team. The latter can be a 'pain specialist' sending the patient around to the physical therapist, psychologist, pharmacist, nutritionist, etc. This is likening a buffet to a gourmet dinner. It won't work guaranteed.

Not all benign chronic pain will disappear but then, pain is ubiquitous and almost always a continuing and important experience of life. Pain must be sampled, appreciated and above all, understood as a part of living. Trying to suppress it with potentially addicting and unpleasant narcotic medications is not only egregious and unthinkable - but second-class medicine at best.

Ernest W. Johnson, MD 